\title{
Choque valorativo e provocação em tiras da Mafalda ${ }^{1}$ Shock of values and provocation in Mafalda's comic strips
}

\author{
Erick Kader Callegaro CORREA* \\ Ana Paula Carvalho SCHMIDT ${ }^{* *}$
}

\begin{abstract}
RESUMO: O presente trabalho é resultado de estudos realizados sobre o Sistema de avaliatividade de Martin e White (2005) e sua aplicação a estudos de gênero. Após seleção do gênero tira em quadrinhos, foram escolhidos exemplares de Mafalda, do autor argentino Quino. A escolha foi motivada pelas características dos textos: escassez lexical e mescla de linguagem verbal e não verbal (MENDONÇA, 2005), que contribuem para a realização do sistema avaliativo. $\mathrm{O}$ objetivo deste trabalho é identificar como as avaliações são realizadas, utilizando-se o aporte do Sistema da avaliatividade (MARTIN; WHITE, 2005). Para isso, foram escolhidas cinco tiras, publicadas em 2012. Primeiramente, os textos foram analisados, de acordo com os recursos lexicogramaticais e algumas expressões idiossincráticas de cada personagem nos quais são evidenciadas características valorativas. A seguir, procurou-se delinear outras formas de avaliação, se inscritas ou evocadas. Após a análise, percebeu-se um padrão semânticodiscursivo de avaliações, tanto inscritas como evocadas, que semanticamente,

ABSTRACT: The present work is the result of studies upon the appraisal system by Martin and White (2005). The corpus chosen to apply such theory is composed by comic strips of Mafalda, from the Argentinian writer Quino. The selection of this genre was based on how lexically low texts and the mixture of verbal and nonverbal language contribute to instantiate the appraisal system. Thus, this work aims to identify how the evaluations are instantiated, using appraisal as theoretical support. Firstly, five comic strips published in 2012 were selected. Secondly, the comic strips were analyzed according to the lexicogrammatical resources and some idiosyncratic expressions of each character in which evaluations were identified. Then, we analyzed how such evaluations take form: whether they are inscribed (explicit) or evoked (implicit). Afterward, a semantic-discursive pattern was noted: the evaluations, either inscribed or evoked, are frequent. Such evaluations are distinct among themselves because they carry, semantically, different values and beliefs
\end{abstract}

\footnotetext{
${ }^{1}$ Este trabalho contou com auxílio do CNPq (processo no 140799/2018-4) para a segunda autora.

*. Doutor em Estudos Linguísticos pela UFSM e professor do curso de Letras - Universidade Franciscana. erickcallegaro@gmail.com

** Doutoranda em Estudos Linguísticos pelo Programa de Pós-Graduação em Letras da Universidade Federal de Santa Maria - UFSM. ORCID: https://orcid.org/0000-0002-5434-6897. anagcarvalho@hotmail.com
} 
carregam consigo valores e crenças opostas que entram em conflito e causam humor. Como num efeito dominó, as avaliações inscritas dão origem a avaliações provocadas, nas quais o autor parece direcionar seu leitor a uma avaliação final do fenômeno cotidiano em jogo.

PALAVRAS-CHAVE: Sistema de avaliatividade. Mafalda. Ironias. Tiras. that are placed to conflict, then, causing humor. As in a domino effect, the inscribed evaluations create the provoked ones, in which the author seems to direct his reader to a final evaluation upon the phenomenon he has placed in the comic strips.

1 Introdução ${ }^{2}$

No momento em que usamos a linguagem, avaliamos ações, comportamentos, acontecimentos, entidades e opiniões. As escolhas lexicogramaticais que configuram nossos textos dão pistas sobre quais posições ideológicas, quais comunidades de crenças e valores compartilhamos e como percebemos o mundo que nos rodeia. Com o objetivo de sistematizar os recursos linguísticos de cunho avaliativo, Martin e White (2005) propõem o Sistema de avaliatividade. Tal sistema oferece um universo de recursos linguísticos e semântico-discursivos a que recorremos para avaliar os vários fenômenos do mundo.

Desse modo, o objetivo que traçamos no presente artigo é descrever como alguns exemplares do gênero tira configuram o sistema de avaliatividade em seus textos. Uma das características do gênero é a economia lexical, ou seja, a linguagem verbal é escassa e se mescla com a linguagem não verbal, que se materializa na idiossincrasia dos personagens e suas expressões e gestos. Resultante da escassez lexical, o leitor necessita realizar leituras além da superfície para compreender o que está em jogo em termos de avaliação e como o autor se posiciona. Por isso, buscamos investigar a existência ou não de um padrão semântico-discursivo nas tiras

\footnotetext{
${ }^{2}$ Agradecemos aos pareceristas anônimos pelas contribuições dadas a uma versão anterior deste artigo.
} 
selecionadas, a fim de compreender como o sistema de avaliatividade é materializado nos exemplares do gênero em questão.

Após sintetizar o objetivo da pesquisa nesta introdução, prosseguimos a narrativa, organizando-a em quatro partes. Na primeira parte (Seção 2), situamos o trabalho teoricamente e delimitamos os conceitos centrais para a análise. A seguir, na segunda parte (Seção 3), apresentamos os procedimentos metodológicos utilizados. Na terceira parte (Seção 4), discutimos como o humor é alcançado nas tiras, em combinação com a mobilização de recursos lexicais para negociar significados nas interações sociais. Por fim, na quarta parte (Seção 5), sugerimos que o humor resulta da articulação de recursos avaliativos pelo escritor, que suscitam choque de posições valorativas, conduzindo o leitor a uma mudança da rota de leitura.

\section{Gramática Sistêmico-Funcional e Sistema de avaliatividade}

Fairclough (2003, p. 26), ao discorrer sobre a multifuncionalidade do texto que Halliday e Matthiessen (2004) propõem com a Gramática Sistêmico-Funcional, afirma que

[..] textos, simultaneamente, representam aspectos do mundo (o mundo físico, o mundo social, o mundo psíquico); ativam relações sociais entre os participantes do evento social e suas atitudes, desejos e valores; coerente e coesivamente conectam partes do texto entre si, e também os textos a seu contexto de situação ${ }^{3}$.

O conceito de multifuncionalidade textual que Halliday e Matthiessen (2004) propõem na GSF (Gramática Sistêmico-Funcional) origina-se das três formas com que

\footnotetext{
${ }^{3}$ Tradução nossa. No original: "That is, texts simultaneously represent aspects of the world (the physical world, the social world, the mental world); enact social relations between participants in social events and attitudes, desires, and values of participants; and coherently and cohesively connect parts of texts together, and connect texts with their situational contexts".
} 
a linguagem é capaz de produzir significados, através da comunicação humana, e que estão incorporados nas orações que construímos.

As escolhas lexicogramaticais de um indivíduo, ao interagir com outros dentro de uma prática social específica, são resultado da relação dialética entre o contexto e a língua: elementos contextuais influenciam tais escolhas, ao mesmo tempo em que a língua, como uma fonte potencial de construção de significados, também influencia o texto final do escritor/falante. Esses elementos são chamados de variáveis do contexto de situação e se constituem em três: campo, relações e modo. $\mathrm{O}$ campo diz respeito ao que se fala ou se escreve, componente que dá conta da representação da realidade. As relações são responsáveis pela manutenção dos papéis que os indivíduos, dentro de uma interação, assumem. Já o modo é a forma como a interação se materializa, seja na modalidade escrita ou na falada. Desses elementos surgem, então, as metafunções da GSF: a metafunção ideacional, a metafunção interpessoal e a metafunção textual.

A metafunção utilizada para que se possa alcançar o objetivo do presente artigo é a metafunção interpessoal, no que tange ao sistema de avaliatividade. Enquanto representamos nossas experiências por meio da metafunção ideacional, também construímos significados interpessoais. Ao interagirmos com outros indivíduos, assumimos papéis de fala e, consequentemente, damos a eles outro papel de fala, caracterizando a interação como um processo de trocas entre ambos os interagentes.

Conforme Vivan (2010), a metafunção interpessoal também é responsável pela avaliação que os interagentes fazem sobre a interação em que ambos se encontram ou sobre o que ambos falam. Acrescenta Cabral (2007, p. 53) que tal metafunção é capaz de

manifesta[r] a participação dos locutores no texto e pode indicar como eles aprovam ou desaprovam, entusiasmam-se ou odeiam, aplaudem ou criticam os seres e os fatos do contexto social, e como esses agentes constroem a identidade de seus ouvintes/falantes, de modo a persuadilos de suas crenças, seus valores, suas opiniões. 
A abordagem que tem o trabalho de explorar e descrever as formas como o produtor textual avalia/julga/sente (sobre) alguém ou algo na interação, mostrando, direta ou indiretamente, sua posição quanto ao que está em jogo, é chamada Sistema de avaliatividade. Segundo White $[2010]^{4}$, um dos principais estudiosos dessa abordagem, usamos tal sistema para

explorar, descrever e explicar a maneira como é usada para avaliar, adotar posições, construir personae textuais e manter as posições interpessoais e as relações [entre os indivíduos]. Portanto, explora como os falantes e produtores textuais julgam outros indivíduos e seus enunciados, objetos materiais, acontecimentos e o estado das relações, com isso formando alianças com aqueles que compartilham tais visões ou distância com aquele que possui visões diferentes ${ }^{5}$.

O Sistema de avaliatividade, em relação à GSF, é uma das realizações da metafunção interpessoal. As avaliações ou as posições ideológicas que os agentes sociais negociam entre si são significados potenciais produzidos não somente em nível lexicogramatical, mas também semântico-discursivo, pois vão além do significado da oração, ou seja, "servem para realizar os significados interpessoais no que tange à avaliação de coisas, comportamento das pessoas e seus sentimentos" (ALMEIDA, 2010, p. 39). Logo, as avaliações que construímos podem ser percebidas pelo uso de estruturas adjetivas, modalizadores, dentre outras, mas também, de uma forma

4 Disponível em: http://www.grammatics.com/appraisal/appraisalguide/unframed/appraisaloverview.htm. Acesso em 07 de mar. 2019.

${ }^{5}$ Tradução nossa. No original: "[...] a particular approach to exploring, describing and explaining the way language is used to evaluate, to adopt stances, to construct textual personas and to manage interpersonal positionings and relationships. Thus it explores how speakers and writers pass judgments on people generally, other writers/speakers and their utterances, material objects, happenings and states of affairs and thereby form alliances with those who share these views and distance themselves from those who don't." 
implícita, na qual devemos recorrer a elementos contextuais para esclarecer que posição ideológica está em jogo.

O sistema em questão apresenta três subsistemas: atitude, engajamento e gradação. O subsistema atitudinal preocupa-se em analisar os sentimentos e/ou reações emotivas que surgem, em suas formas linguísticas, quando estamos em interação e as avaliamos tanto de forma positiva quanto de forma negativa. Logo, as três regiões semânticas cobertas por tal sistema são a emoção, a ética e a estética, as quais dão origem aos três subsistemas atitudinais, respectivamente: afeto, julgamento e apreciação.

O afeto, segundo White [2010], diz respeito às respostas emocionais (positivas ou negativas) ou disposições que o agente social sente em relação a alguém, a algum evento ou estado de coisas. O julgamento é realizado quando o produtor textual critica ou preza, aplaude ou condena o comportamento humano e manifesta crenças e valores nele imbricados. Por último, a apreciação abrange as avaliações que os produtores textuais fazem de alguém, algum evento social ou relação social em termos de sua estética.

Segundo Martin e White (2005), as ocorrências avaliativas do subsistema de atitude podem ser categorizadas em duas: inscrita e evocada, sendo que esta última pode ser provocada ou por convite. A avaliação inscrita ocorre quando há um elemento tipicamente avaliativo, por exemplo, por meio do uso de adjetivos. A evocada, por sua vez, ocorre quando é necessário buscar outros elementos linguísticos para que se chegue à avaliação do escritor/falante. No âmbito da avaliação evocada, isto é, implícita, a provocada ocorre na utilização de um elemento que não é tipicamente considerado avaliativo (como metáfora, metonímia, personificação), construindo um direcionamento para que o leitor/ouvinte acione algum tipo de avaliação. Por fim, a atitude implícita por convite é aquela em que o falante/escritor 
sugere uma avaliação ao ouvinte/leitor, ao recorrer a elementos da metafunção ideacional experiencial ou lógica.

O subsistema de engajamento lida com as formas pelas quais nos engajamos a enunciados avaliativos e como configuramos seu posicionamento em nossas próprias avaliações. Quando estamos em jogo interativo, posicionamos nossas avaliações em referência a enunciados passados (aqueles produzidos pelas comunidades de crenças e valores compartilhadas) e em referência a enunciados futuros. Martin e White (2005) buscam, na perspectiva de Bakhtin (2003), a característica dialógica do enunciado: a realidade da linguagem é a interação verbal, ou seja, ao nos comunicarmos, encontramo-nos em constante diálogo com enunciados previamente construídos e antecipamos os enunciados do nosso leitor/ouvinte.

Logo, Martin e White (2005) separam o subsistema de engajamento em duas grandes áreas: expansão e contração dialógica. A expansão dialógica ocorre quando abrimos alternativas dialógicas para com nosso leitor/ouvinte ao avaliarmos alguma coisa, ou seja, há pouco investimento interpessoal em nossa avaliação. Convidamos nosso leitor/ouvinte a produzir outras avaliações, pois nos distanciamos de nossa proposição avaliativa.

Nessa categoria, há mais dois subsistemas: entretenimento e atribuição. $\mathrm{O}$ subsistema de entretenimento ocorre quando o falante/escritor materializa suas avaliações como uma possibilidade, dessa forma, abrindo espaço para outras vozes em seu texto. No subsistema de atribuição, o escritor/falante traz à sua proposição a subjetividade de uma voz externa, isto é, a avaliação que produz está ancorada em vozes que não são suas.

No fenômeno de contração dialógica, o escritor/falante contrai o espaço para alternativas dialógicas, seja recorrendo a vozes externas, quando o investimento interpessoal é maior, ou quando uma avaliação é rejeitada ou tida como não válida, não verdadeira. 
Nesse campo, há dois subsistemas aos quais o escritor/falante pode recorrer: refutação e declaração. O primeiro divide-se em: negação e contraexpectativa, e ocorre, segundo Martin e White (2005, p. 118): “[quando é] introduzida a alternativa positiva para o diálogo [...] reconhecendo-a [para, consequentemente] negá-la." O segundo, a declaração, é quando nos utilizamos de outras vozes, de forma explícita, para ancorar nossa avaliação, num nível alto de engajamento.

Por último, temos o subsistema de gradação que perpassa tanto o subsistema atitudinal quanto o de engajamento, pois suas materializações lexicogramaticais criam escalas de intensidade e quantidade. Dois subsistemas constituem a gradação: força e foco. Quando falamos em força, Martin e White (2005) constatam que tal campo semântico cobre níveis de intensidade e de quantidade e materializam-se explicitamente no texto em forma de advérbios ou de quantificadores, dentre outros. No subsistema de foco, o escritor/falante suaviza ou intensifica a precisão das categorias semânticas que estão no jogo comunicativo.

\subsection{0 gênero tira}

O gênero em análise, segundo os critérios de categorização de Mendonça (2005), é a tira, um subtipo de histórias em quadrinhos, caracterizada por uma divisão de até quatro quadros, assumindo "formas sequenciais (capítulos de narrativas maiores) ou fechadas (um episódio por dia)" (MENDONÇA, 2005, p. 198), com temática envolta na crítica político-econômica.

Visualmente, trata-se em geral de uma estrutura narrativa, dividida em quadros. Concomitantemente, há a presença de imagens (espaços e tempos diversos, emoções dos personagens materializadas por meio de expressões corporais), balões de fala, "que simbolizam a tomada de turno e o momento de enunciação de cada personagem" (PREDEBON, 2015, p. 80) e também textos verbais. Porém, não há somente a presença da tipologia narrativa. Em tiras, identificamos também a presença 
de argumentação a respeito de uma tese. Para Martin e Rose (2007, p. 12), o propósito social desses gêneros de cunho argumentativo é "persuadir uma audiência do ponto de vista do escritor ${ }^{6 \prime \prime}$. Segundo a autora, é de difícil categorização o gênero em questão, pela diversidade de formas que assume, nos mais diferentes meios de divulgação (jornais, sítios, televisão, dentre outros).

Neste artigo, propomo-nos a analisar as tiras de autoria do argentino Joaquín Salvador Lavado, conhecido como Quino, apelido recebido na infância, no ambiente familiar (LAVADO, 1992). A personagem Mafalda, cujo nome é inspirado nas duas primeiras letras de uma empresa de eletrodomésticos que havia solicitado os desenhos para uma campanha publicitária - Mansfield, surge pela primeira vez em 1963 (LAVADO, 1992). Entretanto, a agência não aprovou os desenhos de Quino e a personagem foi recuperada somente no ano seguinte, quando passou a ser publicada semanalmente no jornal Primera Plana (MOYA, 1993). Com o fechamento deste, em 1965, as tiras tornam-se diárias, no jornal El Mundo (MOYA, 1993). A personagem tornou-se conhecida em outros países latino-americanos e na Europa ainda na década de 1960; entretanto, no Brasil, as primeiras compilações das tiras são publicadas somente no início da década de 1980 (LAVADO, 1992). Mafalda interage nas narrativas com amigos, que serão apresentados nas tiras analisadas aqui: Felipe, retratado como um idealista; Susanita, que parece ser obcecada por meninos e dinheiro; Manolito, construído como o estereótipo de um homem de negócios, simpático ao capitalismo e materialista (MOYA, 1993).

Nessas tiras, além da estrutura narrativa, típica do gênero, há também diversos casos de estruturas argumentativas, apresentadas de forma implícita e materializadas, linguisticamente, em ironias. Concebida, a partir de diferentes perspectivas, como "figura de retórica em que se diz o contrário do que se diz" (DUARTE, 1994, p. 9),

\footnotetext{
${ }^{6}$ Tradução nossa. No original: "to persuade an audience to the writer's point of view [...]".
} 
"construção de linguagem" ou "atitude, [...] marca de personalidade" (BRAIT, 1996, p. 34), a ironia é utilizada para criticar e construir alinhamento da audiência com a perspectiva do escritor/falante (PARTINGTON, 2007). Por sua "natureza altamente avaliativa", a ironia é uma "ferramenta tanto para crítica/controle social quanto para persuasão e não é nenhuma surpresa que seja particularmente comum em textos argumentativos $^{7 \prime \prime}$ (PARTINGTON, 2007, p. 1554). A partir dessa característica irônicoargumentativa, as tiras de Mafalda colocam em jogo conflitos idiossincráticos de cada personagem, utilizando um discurso de crítica a eventos de cunho político ou econômico.

\section{Metodologia}

O objetivo deste trabalho é apresentar uma amostra do funcionamento do sistema valorativo em cinco tiras da Mafalda, do cartunista argentino Quino. As tiras foram publicadas no site http://clubedamafalda.blogspot.com.br, em outubro de 2012. A análise dos textos foi dividida em duas etapas.

Primeiramente, as tiras em quadrinhos foram analisadas, de acordo com o Sistema de avaliatividade, buscando identificar a quais recursos, tanto lexicogramaticais quanto semântico-discursivos, o autor recorre para construir as avaliações. Para que isso se realizasse, foi necessário investigar tanto as ocorrências inscritas quanto as ocorrências evocadas, perpassando pelos subsistemas de atitude, engajamento e gradação.

No segundo momento, as ocorrências avaliativas (inscritas, evocadas e provocadas) foram examinadas e comparadas quanto a sua função nas tiras

\footnotetext{
7 Tradução nossa. No original: "highly evaluative nature of irony" [...] "tool for both social censure/control and for persuasion, and it is no surprise that it is particularly common in argumentative texts".
} 
selecionadas. Por fim, também buscamos interpretar como o processo de humor ocorre a partir das categorias avaliativas encontradas.

\section{Tiras da Mafalda e as ocorrências avaliativas inscritas e evocadas}

Nas cinco tiras analisadas, existem ocorrências de humor, que é alcançado quando valores e crenças entram em jogo conflituoso através das idiossincrasias de cada personagem. O conteúdo das tiras selecionadas para compor o corpus de análise inclui temas como amizade (Figura 1), influência da produção cultural inglesa na América Latina (Figura 2), ciência (Figura 3), conflito de gerações (Figura 4) e materialismo (Figura 5). O elo entre assuntos aparentemente distintos encontra-se no convite à reflexão sobre questões atemporais e universais como poder, ambição, consumismo, que permeiam a crítica social característica das tiras de Mafalda.

A primeira tira (Figura 1), por exemplo, apresenta uma cena em que Mafalda pede emprestada uma agulha a Susanita. Esclarece que não deseja comprá-la, porque irá usá-la uma única vez. No momento do pedido, explicita que são amigas, e os questionamentos em aberto, nos dois últimos quadros, convidam o leitor a refletir sobre o significado de amizade, conforme mostramos a seguir:

Figura 1 - Tirinha 550
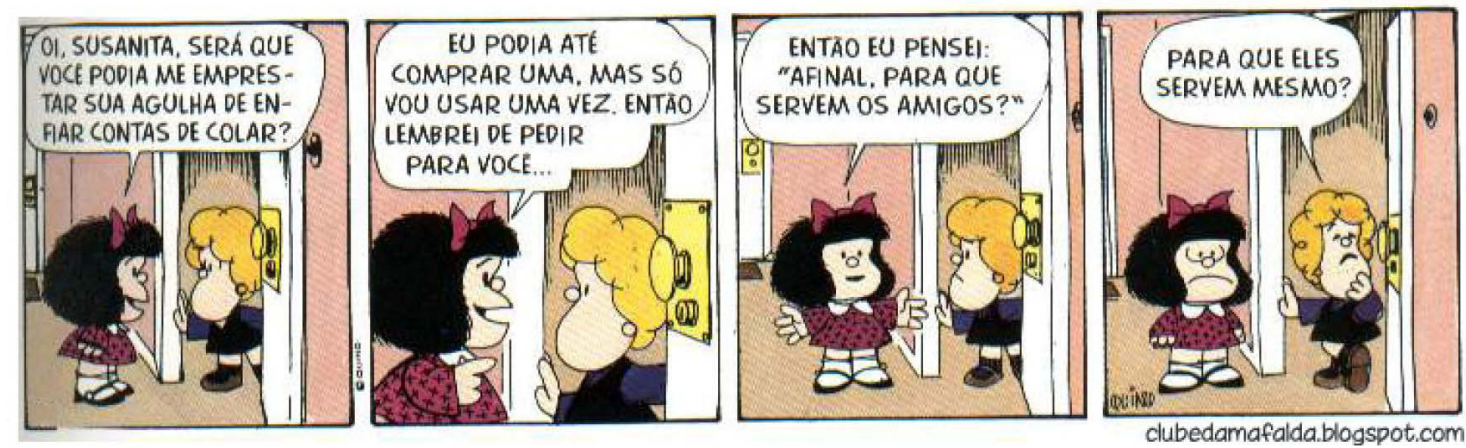

Fonte: http://clubedamafalda.blogspot.com/2012/10/tirinha-550.html\#.XGR-8VVKjIU

Há duas ocorrências avaliativas inscritas nesse texto. Primeiramente, o uso do adjunto "até" fecha parcialmente o espaço discursivo, pois Mafalda antecipa e 
responde a uma possível sugestão de sua interlocutora para que compre uma agulha em vez de pedi-la emprestada. A partir da proposição inicial do diálogo, uma solicitação de empréstimo, Mafalda representa a si mesma como alguém que tem condições de comprar o objeto do qual necessita, contrariando uma potencial expectativa de que ela não tenha capacidade ou meios para adquirir o artefato. Em segundo lugar, destacamos o uso da conjunção adversativa "mas", que também faz parte do subsistema de engajamento, mais especificamente, um recurso de contraexpectativa, pois há duas proposições em jogo. Mafalda investe dialogicamente mais no pedido do que na compra da agulha, ou seja, a personagem apresenta duas proposições e uma delas (a proposição da compra da agulha) é posta como substituível pela outra (a proposição do pedido).

No último quadrinho, há uma ocorrência de avaliação evocada por convite. Martin e White (2005) e Almeida (2010) apontam que a avaliação implícita pode ocorrer por meio de significados ideacionais. Nesse caso, Mafalda avalia o conceito de amizade como algo relacionado à utilidade, capacidade ou incapacidade de prover bens, serviços ou informações, ao selecionar o processo material "servir" em relação ao participante "amigos". Susanita, por sua vez, reflete sobre a questão trazida em forma de pergunta retórica (Para que eles (os amigos) servem mesmo?). Porém, tal pergunta retórica parece ter o objetivo de causar reflexão avaliativa, ou seja, depois da leitura da tira, fazer com que o leitor se pergunte sobre o propósito de uma amizade.

Na segunda tira (Figura 2), também identificamos ocorrência tanto de avaliação inscrita quanto de evocada. De forma explícita, o marcador "não" é um recurso de contração dialógica, pois responde à proposição de que existem pessoas que gostem de Beatles, com a condição de que entendam as letras, que estão em língua inglesa. 
Figura 2 - Tirinha 552
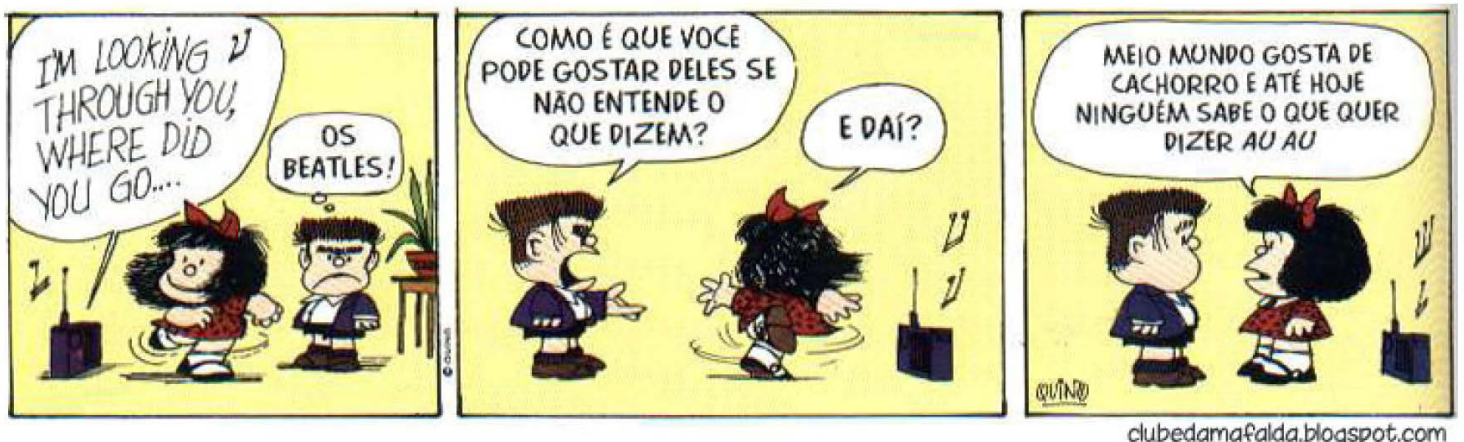

Fonte: http://clubedamafalda.blogspot.com/2012/10/tirinha-552.html\#.XGR-xlVKjIU

No segundo quadro, Manolito, implicitamente, questiona o critério de seleção de preferências musicais de Mafalda. Na visão do menino, a valoração de uma peça musical deve passar pela compreensão da letra. No terceiro quadro, o uso de indefinição contrastada para indicar número de pessoas ("meio mundo" e "ninguém") suporta o argumento de que avaliações valorativas independem da compreensão da linguagem do alvo de afeto ou apreciação. Há que se considerar também a situacionalidade da personagem, uma menina latino-americana, cuja narrativa se desenvolve em um contexto histórico de Guerra Fria e polarização entre os sistemas capitalista e socialista. Consequentemente, os países recebiam influência da produção cultural do polo com o qual se alinhavam ideologicamente. No caso da América Latina, houve e ainda há significativa influência cultural de países de língua inglesa que exercem hegemonia global.

Na terceira tira, Manolito, Felipe e Mafalda conversam sobre uma notícia jornalística. O conteúdo da notícia trata da concessão de um prêmio pela Academia Real Sueca de Ciências para descobertas que tragam avanços para a humanidade em seis diferentes áreas de produção do conhecimento, sendo uma delas a Física. 
Figura 3 - Tirinha 553
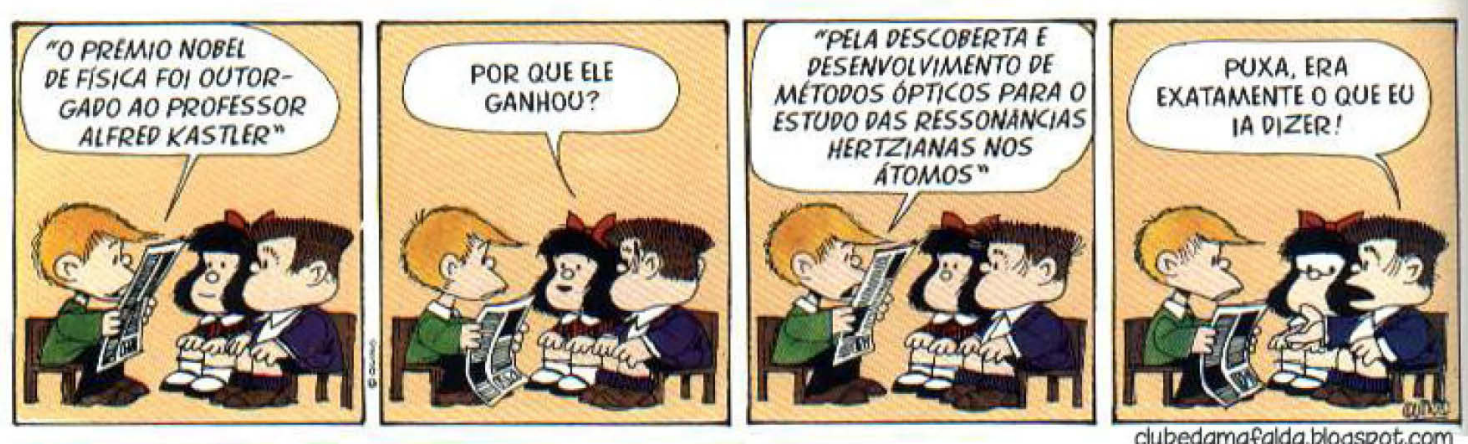

Fonte: http://clubedamafalda.blogspot.com/2012/10/tirinha-553.html\#.XGR-k1VKjIU

Por meio do adjunto "exatamente", recurso do subsistema de gradação, Manolito dá força a sua fala, que antes era de Filipe, ou seja, intensifica-a. Entretanto, outro tipo de avaliação é evocada. No momento da intensificação, Manolito também avalia o quão atualizado ele está em relação aos acontecimentos que permeiam as gratificações do Prêmio Nobel. Logo, avalia e também julga a sua capacidade, que são avaliações típicas do subsistema de atitude, no que diz respeito a julgamento por estima social.

Pode-se inferir, ainda, uma segunda avaliação evocada, por meio de linguagem corporal: a expressão facial de Mafalda e Filipe para Manolito. No momento em que Manolito assume uma posição de "sabe-tudo", as outras personagens o olham de forma surpresa. Interpretamos esse olhar como uma avaliação evocada, na qual o subsistema atitudinal perpassa: Filipe e Mafalda parecem estar perplexos com a pretensão de Manolito, que se autoavalia como portador de informações, sem ao menos ter conhecimento sobre elas. Logo, a avaliação atitudinal de capacidade das outras personagens, em relação a Manolito, é negativa, pois, pelo olhar, julgam-no pretensioso.

$\mathrm{Na}$ quarta tira, que retrata a questão do conflito intergeracional, há um entrecruzamento entre os limites dos recursos de apreciação e afeto: 
Figura 4 - Tirinha 554
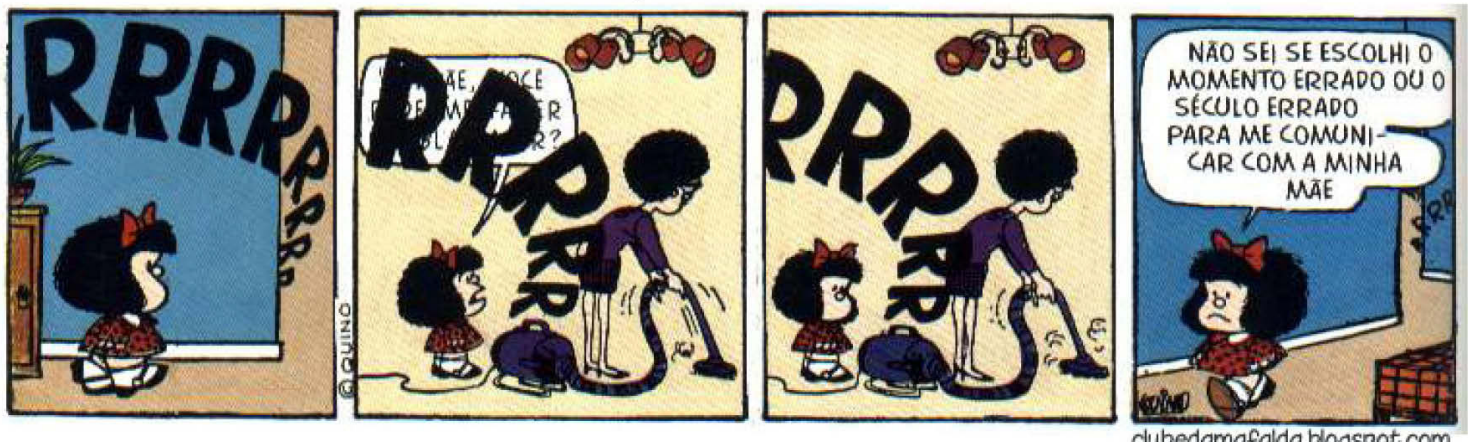

Fonte: http://clubedamafalda.blogspot.com/2012/10/tirinha-554.html\#.XGR-W1VKjIU

Ao qualificar "momento" e "século" como "errado[s]", Mafalda avalia negativamente a possibilidade de buscar estabelecer diálogo com a mãe. Há, também, uma avaliação atitudinal de afeto, realizada não verbalmente pela expressão facial triste de Mafalda. Pode-se interpretar que a personagem se sente "triste" por estar no momento e/ou século errado. Nessa avaliação, o recurso implícito "triste" é o sentimento negativo que Mafalda possui, que pode ser classificado como um indicador de afeto. Com o marcador "não", tem-se um recurso do subsistema de engajamento, por meio do qual Mafalda exclui a proposição de que exista um momento ou século certo para se comunicar com sua mãe. Em adição, no modo visual, o autor questiona e critica a transformação pela qual o ambiente doméstico passou no século $X X$, devido à chegada da tecnologia, representada na tira pela figura de um aspirador.

Na quinta tira, há sete avaliações inscritas e uma avaliação evocada.
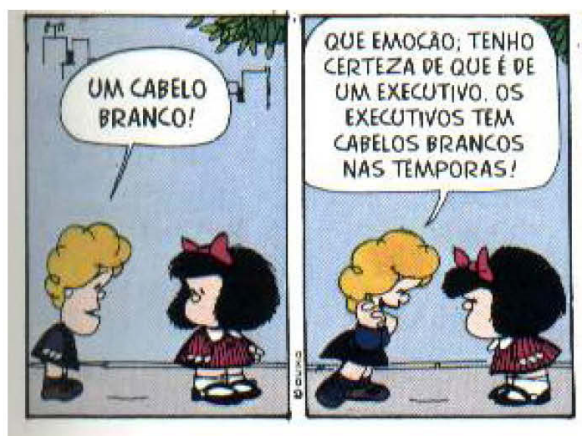

Figura 5 - Tirinha 558

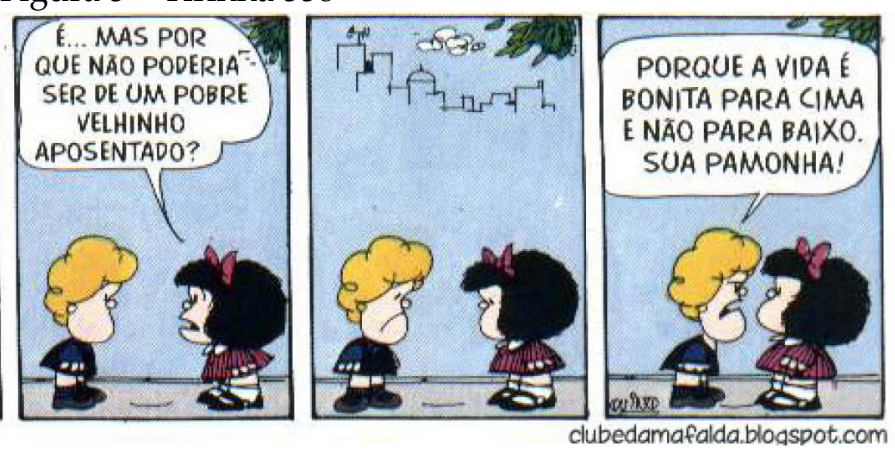

Fonte: http://clubedamafalda.blogspot.com/2012/10/tirinha-558.html\#.XGR-AlVKjIU 
A primeira ocorrência está situada na locução "que emoção" na fala de Susanita, que avalia o descobrimento de um cabelo branco no chão. Tornando a locução um epíteto, tem-se "emotivo", ou seja, mostra a avaliação afetiva e positiva (subsistema de atitude) de Susanita sobre o seu achado. A segunda ocorrência está na primeira fala de Mafalda, pelo uso do recurso "não" como negação de uma proposição anterior: a personagem tenta negar que o dono do cabelo branco seja um executivo, e diz que pode ser de um pobre velhinho aposentado.

Na mesma fala, identificamos a terceira e a quarta ocorrência. $\mathrm{O}$ excerto "pobre velhinho" acarreta em sua semântica duas avaliações: a primeira através do vocábulo "pobre" e a segunda pelo sufixo "-inho". Se Mafalda nega que é de um executivo financeiramente bem-sucedido, conforme Susanita, o adjetivo pobre avalia a condição financeira do velhinho, logo, encaixa-se no subsistema atitudinal, como elemento de julgamento, no que tange à normalidade do avaliado. Porém, o sufixo "-inho" não tem classificação como elemento de ocorrência avaliativa nos estudos de Martin e White (2005), pois tal sufixo diminutivo não existe em inglês, língua na qual os estudos sobre avaliatividade foram construídos.

Portanto, no presente artigo, classificamos tal sufixo como uma realização do subsistema gradação e um recurso da força por intensificação, pois ele tem a capacidade de abrandar a palavra na qual foi utilizado. Vale ressaltar que ele se torna, também, um outro recurso avaliativo, pois o subsistema atitudinal se entrecruza com a avaliação de gradação. Mafalda, ao dizer "velhinho", julga que a idade avançada do ser humano é fator de capacidade, isto é, chama-o de coitado, incapaz.

A quinta e a sexta ocorrência são mapeadas na fala de Susanita, em que a palavra "vida" é avaliada duas vezes, uma de forma inscrita e outra de forma provocada. A inscrita ocorre com o adjetivo "bonita”, recurso atitudinal de apreciação. A provocada depende de outra avaliação inscrita, o uso recurso de negação "não", pois não há na fala da personagem que a vida é feia. Ao recorrer ao "não", a proposição 
avaliativa de que a vida não é bonita fica implícita. Por último, Susanita chama Mafalda de "pamonha", configurando-se na sétima avaliação, de significado atitudinal de julgamento negativo, pois aquela pressupõe que a amiga Mafalda é pateta por não ter a mesma percepção que ela sobre a vida.

\section{Considerações finais}

Com base no Sistema de avaliatividade, o jogo de valores nas tiras analisadas são ocorrências, tanto inscritas como evocadas, de avaliações de contraexpectativa. $\mathrm{O}$ autor seleciona valores e opiniões, que se materializam nas características próprias de cada personagem e as posiciona conflituosamente, produzindo uma mudança de rota de leitura.

Na primeira tira, a avaliação inscrita de Mafalda, na qual a proposição do pedido ultrapassa a proposição da compra do objeto, entra em conflito com a avaliação sobre a amizade de Susanita, que é evocada pela pergunta retórica. Na segunda tira, duas avaliações entram em choque: Manolito, que questiona a preferência pessoal e julga que as pessoas não são capazes de gostar de coisas que não entendem, e o julgamento de Mafalda, que propõe o contrário. Na terceira, estão combinadas, também, duas avaliações. Na forma inscrita, Manolito intensifica a sua autoavaliação como capaz e inteligente. Na forma evocada, as outras outras personagens respondem, por meio de linguagem corporal, avaliando-o negativamente, em termos de nível de conhecimento (capacidade).

Já na quarta tira, a avaliação sobre a possibilidade de comunicação entre mãe e filha mostra a impossibilidade de duas pessoas de gerações diferentes de se comunicarem. A avaliação inscrita, realizada pelo "não", põe em jogo duas proposições avaliativas: que existe um momento e um século "certo" para a comunicação entre ambas mãe e filha, e que Mafalda está num momento ou século "errado". Na última tira, Mafalda e Susanita parecem discordar sobre como se deve 
nivelar o grau de otimismo sobre fatos mundanos. A primeira possui uma posição avaliativa mais realista em relação ao cabelo branco encontrado, enquanto a segunda se posiciona de forma exageradamente otimista, o que resulta no "xingamento" que pronuncia no final da história.

Sob o olhar do Sistema de avaliatividade, podemos perceber que, quando o autor configura duas ocorrências avaliativas, sejam elas inscritas ou evocadas, de forma conflituosa, o gênero "tira" é capaz de causar humor: uma situação na qual avaliações são postas em "guerra" torna-se engraçada, risível, pois há um desvio da direção de leitura.

O humor da situação, causado pelas avaliações contrárias, causa, também, um outro resultado: a avaliação evocada provocada. Como citado no referencial teórico, a avaliação evocada provocada ocorre quando o autor insere em seu texto um termo que não é tipicamente avaliativo, mas é capaz de direcionar o leitor a uma reflexão avaliativa.

É exatamente o que ocorre como resultado do choque entre avaliações opostas: nos quadrinhos, o autor parece direcionar o seu leitor, provoca-o a uma reflexão de cunho avaliativo, que nasce do confronto entre os valores/avaliações contrárias. Logo, podemos inferir que o padrão semântico-discursivo das tiras analisadas constitui-se em dois: numa situação cotidiana, duas avaliações entram em choque, pois são contrárias, ou seja, norteadas por valores contrários, e uma avaliação evocada provocada, criada com o objetivo de direcionar o leitor a uma reflexão valorativa sobre as ideologias em jogo.

\section{Referências}

ALMEIDA, F. S. D. P. A avaliação na linguagem: os elementos de atitude no discurso do professor - um exercício em análise do discurso sistêmico-funcional. São Carlos: Pedro \& João Editores, 2010. 
BAKHTIN, M. Os gêneros do discurso. In: BAKHTIN, M. Estética da criação verbal. São Paulo: Martins Fontes, 2003, p. 261-306.

BRAIT, B. Ironia em perspectiva polifônica. Campinas, São Paulo: Editora da Unicamp, 1996.

CABRAL, S. R. S. A mídia e o presidente: um julgamento com base na teoria da valoração. 2007. 249 f. Tese (Doutorado em Letras. Estudos Linguísticos) Universidade Federal de Santa Maria, Santa Maria, 2007.

CLUBE da Mafalda. Disponível em: http://clubedamafalda.blogspot.com. Acesso em 29 mar. 2019.

DUARTE, L. P. Conferência de abertura "Ironia, humor e fingimento literário". In: XXVI SENAPULLI, 1994, Campinas. Anais do XXVI SENAPULLI - Humor e ironia na literatura. Campinas, 1994. p. 9-16.

FAIRCLOUGH, N. Analysing discourse: textual analysis for social research. Londres: Routledge, 2003. DOI https://doi.org/10.4324/9780203697078.

HALLIDAY, M. A. K.; MATTHIESSEN, C. An introduction to functional grammar. 3. ed. Nova Iorque: Hodder Education, 2004.

LAVADO, J. S. Todo Mafalda. Barcelona: Editorial Lumen S.A., 1992.

MARTIN, J. R.; ROSE, D. Working with discourse: meaning beyond the clause. Londres/Nova Iorque: Continuum, 2007.

MARTIN, J.; WHITE, P. R. R. The language of evaluation: appraisal in English. Nova Iorque: Palgrave, 2005. DOI https://doi.org/10.1057/9780230511910.

MENDONÇA, M. R. de S. Um gênero quadro a quadro: a história em quadrinhos. In: DIONISIO, A. P.; MACHADO, A. R.; BEZERRA, M. A. Gêneros textuais \& ensino. Rio de Janeiro: Lucerna, 2005. p. 194-207.

MOYA, A. de. História da história em quadrinhos. 2. ed. São Paulo: Editora Brasiliense, 1993.

PARTINGTON, A. Irony and reversal of evaluation. Journal of Pragmatics, v. 39, n. 9, p. 1547-1569, 2007. DOI https://doi.org/10.1016/j.pragma.2007.04.009 
PREDEBON, N. R. C. Do entretenimento à crítica: letramento multimodal crítico no livro didático de inglês com base em gêneros dos quadrinhos. 2015. 241 f. Tese (Doutorado em Letras. Estudos Linguísticos) - Universidade Federal de Santa Maria, Santa Maria, 2015.

VIVAN, E. G. S. Interação e discurso: uma visão da linguística sistêmico-funcional. In: FERNANDEZ, D.; GHIO, E. El discurso en español y portugués: estudios desde una perspectiva sistémico-funcional. Santa Fe: Centro de Publicaciones de la Universidad Nacional del Litoral, 2010, p. 231-269.

WHITE, P. R. R. Appraisal: an overview. [2010]. Disponível em: http://www.grammatics.com/appraisal/appraisalguide/unframed/appraisaloverview.htm. 